\title{
A AMPLIFICAÇÃO DA DEMANDA NA CADEIA DE SUPRIMENTOS: UMA ANÁLISE NO SETOR DE MERCEARIA BÁSICA
}

\section{DEMAND AMPLIFICATION IN THE SUPPLY CHAIN: AN ANALYSIS ON THE GROCERY INDUSTRY}

\author{
Daniela de Castro Melo ${ }^{1}$; Rosane Lucia Chicarelli Alcantara ${ }^{2}$ \\ ${ }^{1}$ Universidade Federal do Triângulo Mineiro - UFTM - Uberaba - Brasil \\ daniela_c_melo@yahoo.com.br \\ ${ }^{2}$ Universidade Federal de São Carlos (UFSCar) - São Carlos - Brasil \\ rosane@dep.ufscar.br
}

\begin{abstract}
Resumo
A gestão da demanda é um tema emergente no campo de conhecimento da gestão da cadeia de suprimentos. $O$ que se busca com a gestão da demanda é a rápida e adequada integração das necessidades originadas do mercado na direção dos fornecedores, de modo a balancear e alinhar estrategicamente a demanda com a capacidade operacional ao longo da cadeia de suprimentos. $O$ alinhamento da demanda na cadeia de suprimentos enfrenta dificuldades progressivas como, por exemplo, a falta de precisão nas informações, perdas devido a desperdícios, falta ou excesso de estoques, provocando ineficiência e ineficácia no atendimento a clientes, redução do giro de estoque e alto índice de obsolescência agravada pela grande diversidade de produtos. Assim, o objetivo desta pesquisa foi identificar e analisar os desafios da implantação do processo de gestão da demanda na cadeia de suprimentos de produtos de mercearia básica. O método de pesquisa foi o estudo de caso considerando como empresa focal o atacadista distribuidor Martins e nove de seus principais fornecedores de produtos de mercearia básica. Os resultados mostram que o compartilhamento de informações, desenvolvimento de um plano de negócios em conjunto e o seu acompanhamento diminuem o efeito da amplificação da demanda na cadeia de suprimentos analisada. Porém, verifica-se que mesmo diante de um alto nível de transparência de informações, abertura e confiança entre os agentes, como também compartilhamento de metas conjuntas, ainda existe a amplificação da demanda, ocasionando o efeito chicote.
\end{abstract}

Palavras-chave: amplificação da demanda; gestão da demanda; gestão da cadeia de suprimentos.

\section{Introdução}

A gestão da demanda é um tema emergente no campo de conhecimento da gestão da cadeia de suprimentos. O que se busca com a gestão da demanda é a rápida e adequada integração das necessidades originadas do mercado na direção dos fornecedores, de modo a balancear e alinhar estrategicamente a demanda com a capacidade operacional ao longo da cadeia de suprimentos. 
O trabalho acadêmico de Croxton et al (2008) é um dos poucos que lida com a gestão da demanda de uma forma mais abrangente. Os autores desenvolveram um modelo conceitual para a implementação bem sucedida da gestão da demanda, com foco na previsão de demanda e na sincronização da oferta e da demanda. Porém, não fornecem evidência empírica para o modelo proposto. Desta forma, a evidência empírica de algum impacto positivo da gestão da demanda no desempenho da cadeia de suprimentos e seus desafios é geralmente escassa e tem em sua maioria caráter anedótico (BOWER, 2006; MILLIKEN, 2008).

Autores como Esper et al (2010), Hilletofth, Ericsson e Christopher (2009), Juttner, Christopher e Baker (2007), Mentzer e Moon (2005), Rexhausen, Pibernik e Kaiser (2012), Voluntary Interindustry Commerce Standards - VICS (2010) propuseram abordagens para a gestão da demanda na cadeia de suprimentos destacando suas interações e sua importância, porém não apresentaram os desafios para implantar o processo de gestão da demanda.

Além disso, percebe-se que as contribuições da literatura geralmente focam práticas isoladas de gestão da demanda como, por exemplo, previsão de demanda; planejamento de vendas e operações (S\&OP); planejamento, previsão e reposição colaborativos (CPFR); segmentação da demanda (MELO; ALCÂNTARA, 2011, 2012).

Assim, constata-se que há pouca informação disponível sobre a gestão da demanda em cadeias de suprimentos (ADEBANJO, 2009; MELO; ALCÂNTARA, 2011; 2012; TAYLOR, 2006; TAYLOR; FEARNE, 2006; TROQUE, 2003). As abordagens identificadas na literatura (CROXTON et al, 2008; ESPER et al, 2010; HILLETOFTH; ERICSSON; CHRISTOPHER, 2009; JUTTNER; CHRISTOPHER; BAKER, 2007; MENTZER; MOON, 2005; VOLUNTARY INTERINDUSTRY COMMERCE STANDARDS - VICS, 2010) não exploraram empiricamente os desafios para implementar o processo de gestão da demanda.

Diante da necessidade de trabalhos que explorem a gestão da demanda, uma lacuna importante identificada na literatura está relacionada aos desafios da implantação da gestão da demanda na cadeia de suprimentos. Para diminuir esta lacuna, este artigo apresenta a seguinte questão de pesquisa: quais são os desafios para a implantação da gestão da demanda na cadeia de suprimentos de produtos de mercearia básica e como reduzir ou eliminar seus efeitos?

Neste sentido, o objetivo desta pesquisa é identificar e analisar os desafios no processo de gestão da demanda na cadeia de suprimentos de produtos de mercearia básica. O método de pesquisa foi o estudo de caso considerando como empresa focal o atacadista distribuidor Martins e nove de seus principais fornecedores de produtos de mercearia básica (Bombril, Colgate-Palmolive, Diageo, Garoto, Johnson \& Johnson, Kraft, L’Oréal Brasil, Procter \& Gamble, Unilever).

A importância e a contribuição desta pesquisa estão justificadas pelo fato da gestão da demanda sob a perspectiva da gestão da cadeia de suprimentos ser um conceito novo, ainda não 
consolidado, que carece de mais estudos e definições. Além disso, destaca-se o fato de a pesquisa trabalhar com casos práticos que abordam as dificuldades da implantação da gestão da demanda, apresentando e discutindo as experiências de empresas. Com isso, espera-se contribuir para uma melhor compreensão e visão mais ampla da gestão da demanda que aponte caminhos a serem adotados pelas organizações para a superação dos desafios atuais de conciliar as necessidades dos clientes e as capacidades da cadeia de suprimentos.

Por fim, os resultados desta pesquisa podem despertar o interesse de outros setores industriais a desenvolverem estratégias para eliminar ou reduzir as dificuldades de implantar o processo de gestão da demanda entre elos da cadeia de suprimentos.

$\mathrm{O}$ artigo está estruturado em quatro partes. Inicialmente, no referencial teórico, são discutidos aspectos conceituais da gestão da demanda e seus desafios. Na sequência, é apresentado o método de pesquisa e em seguida, os seus resultados. Por fim, são apresentadas as conclusões.

\section{Desafios da gestão da demanda na cadeia de suprimentos}

Mentzer et al (2001) definem a gestão da cadeia de suprimentos como a coordenação sistêmica e estratégica das funções tradicionais e táticas de negócio dentro de uma empresa e entre empresas ao longo da cadeia de suprimentos, com o objetivo de melhorar os resultados de longo prazo da firma individualmente e da cadeia de suprimentos como um todo. A gestão da cadeia de suprimentos para o Global Supply Chain Forum (GSCF) significa a integração dos processos-chave de negócio desde o usuário final até o fornecedor original que provê produtos, serviços e informações que agregam valor para os clientes e outros stakeholders. Assim, a gestão da demanda é um dos oito processos da gestão da cadeia de suprimentos (CROXTON et al, 2008; LAMBERT, 2004; LAMBERT; COOPER, 2000; LAMBERT, COOPER, PAGH, 1998).

Os conceitos e objetivos da gestão da demanda discutidos por diversos autores (CROXTON et al 2008; HILLETOFTH; ERICSSON, 2007; HILLETOFTH; ERICSSON; CHRISTOPHER, 2009; JUTTNER; CHRISTOPHER; BAKER, 2007; MENTZER et al, 2007; MENTZER; MOON, 2005; PIRES, 2009; RAINBIRD, 2004; VOLLMANN et al, 2004; WALTERS, 2006; WALTERS; RAINBIRD, 2004) pressupõem que a gestão da demanda não pode ser considerada uma atividade resumida a previsão de vendas ou um processo isolado de uma função organizacional específica ou de uma única empresa. Os autores defendem um conceito mais abrangente que envolve a criação de sinergias entre a gestão de operação e de marketing com objetivo de compreender o mercado e desenvolver ações sincronizadas com a estratégia da empresa, capacidade produtiva e atendimento das necessidades do consumidor final.

Muito se tem discutido sobre a gestão da cadeia de suprimentos. Porém ainda são identificadas algumas dificuldades em sua implantação. Segundo Fawcett e Magnan (2002), apesar 
dos benefícios da integração e colaboração entre os membros da cadeia de suprimentos, poucas empresas alcançam o potencial da integração: cerca da metade das firmas pesquisadas estão trabalhando com a integração dentro da empresa, um terço das empresas focam seus esforços de integração com os fornecedores do primeiro nível da cadeia, pouco esforço de integração entre outros níveis.

Segundo Ballou (2006), isto ocorre provavelmente devido às dificuldades para alcançar colaboração efetiva e a algumas limitações como, por exemplo, resistência no compartilhamento de informações. Um fluxo de informação transparente na gestão da cadeia de suprimentos pode ser a chave para reduzir as distorções da demanda (BALJKO, 1999; LEE; PADMANABHAN; WHANG, 1997; PAIK; BAGCHI, 2007).

A literatura da gestão da cadeia de suprimentos frequentemente sugere que a demanda no ponto de consumo deve ser um direcionador para toda a cadeia de suprimentos. Porém, em nenhuma das cadeias estudadas por Taylor (2006) e Taylor e Fearne (2006) os dados do ponto de vendas foram transferidos mais do que para o fornecedor imediato. As pesquisas identificaram a necessidade de todos os elos da cadeia trabalharem em conjunto para que os dados se tornem acessíveis mais rapidamente e mais amigáveis para as organizações a jusante na cadeia. Há necessidade de desenvolver diretrizes coordenadas para a produção, estoque e entrega ao longo de toda a cadeia baseado na demanda de consumo do que em previsões orçamentárias.

O objetivo da gestão da cadeia de suprimentos é sincronizar oferta e demanda buscando a redução dos custos e melhoria na satisfação dos clientes (CHRISTOPHER; TOWILL, 2001). Assim, o nível de distorção da demanda pode ser um indicador de efetividade na cadeia de suprimentos. Porém, segundo Taylor (2006), o direcionador do planejamento da demanda é frequentemente o plano orçamentário de vendas do que a demanda atual de consumo.

Bailey e Francis (2008) analisaram as práticas de colaboração entre os agentes da cadeia de suprimentos. Mesmo diante de um alto nível de transparência de informações, abertura e confiança entre os agentes, ainda existe uma distorção significativa da demanda. Os autores reforçam que apenas o compartilhamento de informações não é suficiente para diminuir o efeito da amplificação da demanda (efeito chicote), sendo necessários outros fatores como, por exemplo, estratégia, resultando em compartilhamento de visão, objetivos e suporte operacional nos indicadores de desempenho na cadeia de suprimentos. Além disso, não há mecanismos de controle e feedback das situações que causam as distorções da demanda, havendo a necessidade medir a efetividade dos processos de gestão da demanda nas empresas (BAILEY; FRANCIS, 2008).

De acordo com Chen et al (2003), Fioriolli e Fogliatto (2009), Lee, Padmanabhan e Whang (1997), o efeito chicote gera consequências locais e sistêmicas para fabricantes, distribuidores e varejistas. Entre as consequências locais, destacam-se: 1) baixos níveis de serviço, gerados pela 
dificuldade de amortecer, em tempo hábil, as variações extremas da demanda; 2) vendas perdidas em função das rupturas de estoques geradas pelas variações extremas da demanda; 3) aumentos dos estoques de segurança, com vistas à recuperação dos níveis de serviço que garantam a competitividade da estrutura; 4) aumento no número de reprogramações de produção para cobrir emergências; e 5) gestão ineficiente de recursos locais, como pessoal, equipamentos e capital.

Entre as consequências sistêmicas, destacam-se: 1) elevação dos custos relacionados a estoques na cadeia de suprimentos em razão do aumento dos estoques locais, em cada um dos pontos do sistema; 2) queda do retorno sobre o capital investido nas operações da cadeia de suprimentos; 3) queda da produtividade dos funcionários que atuam nos processos produtivos ao longo da cadeia de suprimentos; 4) processo decisório reativo, principalmente em função dos picos de demanda, causando ruptura de planejamento; e 5) gestão ineficiente dos recursos da cadeia de suprimentos como um todo, em decorrência das ineficiências locais e da dificuldade de integração das operações da cadeia (CHEN et al 2003; FIORIOLLI; FOGLIATTO, 2009; LEE; PADMANABHAN; WHANG, 1997).

Baljko (1999) recomenda o trabalho conjunto entre os membros da cadeia para determinar a possível causa do efeito por meio das parcerias estratégicas, além da utilização de tecnologia de informação que permita aumentar a velocidade de comunicação e reduzir o tempo de resposta (lead time).

Segundo Mangini, Moori e Perera (2007), as variáveis relevantes da amplificação da demanda podem ser 'causadoras' ou 'amplificadoras'. No primeiro caso, as variáveis responsáveis pelas distorções da demanda são evidenciadas pelo comportamento de compra aleatório do consumidor final justificadas pela incerteza da demanda e variação de preço. Essas variáveis estão fortemente relacionadas aos consumidores finais que procuram produtos de baixo preço e promoções efetuadas pelas lojas varejistas.

Por outro lado, a principal variável amplificadora é a falta de compartilhamento de informações entre as empresas, gerando desequilíbrio dos estoques. Os fabricantes de alimentos não têm uma percepção clara do consumidor final e planejam a produção orientada por previsões e não pela demanda, afetando a gestão da cadeia de suprimentos por meio da manufatura e entregas urgentes de produtos (MANGINI; MOORI; PERERA, 2007).

Para Croxton et al (2008), o processo de formulação da previsão deve envolver diversas áreas da empresa. As previsões devem ser comunicadas internamente para outras áreas que são afetadas por elas. Além disso, a empresa precisa determinar que dados serão compartilhados com outros membros da cadeia de suprimentos.

Christopher e Towill (2000) identificaram que muitas organizações são direcionadas por previsões ao invés de ser direcionadas pela demanda. Isto acontece porque as empresas têm 
dificuldade em capturar dados de mercado, dos consumidores, sendo forçadas a desenvolver previsões baseadas em vendas passadas ou entregas e converter estas previsões em estoque. Croxton et al (2008) propõem que a gestão da demanda deve incluir a identificação de formas de reduzir a variabilidade da demanda e aumentar a flexibilidade em reagir com mais rapidez em situações imprevisíveis. A cadeia de suprimentos que melhor conseguir reduzir incertezas e variabilidade alcançará vantagem competitiva.

O aumento da flexibilidade pode influenciar a confiabilidade, qualidade, custo e rapidez do processo, mas é preciso determinar o quanto de flexibilidade é necessário. Para isto, é importante compreender as necessidades do cliente, os padrões de demanda e as capacidades em toda a cadeia de suprimentos. Uma vez compreendido o quanto de flexibilidade é necessário, deve-se procurar formas de alcançá-la. Isto envolve um trabalho conjunto com outras funções da organização, como também com clientes e fornecedores para determinar onde na cadeia de suprimentos existem oportunidades de aumentar flexibilidade (CROXTON et al, 2008).

A coleta de dados deve compreender um número significativo de fontes que ofereçam dados confiáveis, tornando uma das atividades mais importantes para a construção da previsão (CROXTON et al, 2008). Segundo Taylor (2006), a especificação clara dos dados requeridos e o estabelecimento de sistemas para coletar estes dados são pré-requisitos para desenvolver uma abordagem mais sincronizada para a gestão da demanda.

Rexhausen, Pibernik e Kaiser (2012) ressaltam que a gestão da demanda eficiente impacta de forma positiva e substancial o desempenho da cadeia de suprimentos como um todo e classificam como dimensões da gestão da demanda a segmentação da demanda e a adesão à gestão da demanda, além da previsão de demanda e S\&OP. Os autores defendem que a implementação da previsão de demanda, segmentação da demanda e S\&OP podem não ser suficientes para uma empresa alcançar desempenho superior em gestão da demanda. Assim, os autores destacam que o nível de adesão aos processos da gestão da demanda, ou seja, se são bem definidos, implementados e rigorosamente cumpridos, desempenha um papel importante para uma empresa para desenvolver capacidades superiores de gestão da demanda.

Portanto o principal desafio da gestão da demanda consiste em reduzir ineficiências e atenuar ou eliminar a amplificação da demanda ao longo da cadeia de suprimentos, de modo que seja possível otimizar o uso dos recursos empregados em seus diferentes níveis. Isto depende do grau de conhecimento que se tem sobre as suas causas e sobre a sua intensidade. Assim, o desenvolvimento de uma abordagem mais sistemática e integrada de gestão da demanda na cadeia de suprimentos pode resultar na melhoria do serviço prestado ao cliente, contribuindo para um nível maior de disponibilidade do produto. Isto também pode reduzir os custos pela diminuição das 
perdas de produtos, dos estoques e fornecer uma base mais eficiente para os processos de produção e entrega.

\section{Metodologia}

O método estudo de caso foi adotado nesta pesquisa. Segundo Yin (2005, p.32), "um estudo de caso é uma investigação empírica que investiga um fenômeno contemporâneo dentro do contexto da vida real, especialmente quando os limites entre fenômeno e contexto não estão claramente definidos". O estudo de caso realizado nesta pesquisa se justifica por ser um caso representativo e revelador, conforme será discutido nos próximos parágrafos.

Para atingir o objetivo proposto, a pesquisa empírica precisava envolver empresas pertencentes a uma cadeia de suprimentos que apresentassem as melhores práticas de gestão da demanda. A empresa Martins trabalha com 16.000 itens de produtos em diversos segmentos de negócio (farmácia, eletrônicos e informática, varejo alimentar, materiais de construção e veterinário), atua em todas as cidades do Brasil com 370.000 clientes, possui uma rede de supermercados independentes com quase 1.300 lojas, possui diversos centros de distribuição, mais de 6.000 vendedores, uma estrutura de televendas com 1.000 funcionários, é líder nacional como empresa atacadista distribuidora com faturamento em 2011 de R \$ 3,43 bilhões (RANKING ABAD/ NIELSEN, 2012). Assim, conforme os dados mencionados, a empresa Martins apresenta uma complexidade de gestão da demanda, sendo líder de um setor que é responsável por 51,8\% do mercado de consumo do varejo mercearil (alimentos, bebidas, limpeza, higiene e beleza) segundo dados do Ranking ABAD/Nielsen (2012).

Além disso, a empresa Martins desenvolve com os principais fornecedores o Joint Business Planning (JBP - Planejamento Conjunto do Negócio), estabelecendo um plano de negócios com o fornecedor para atingir metas estabelecidas em conjunto. A empresa também possui uma cultura interna de compartilhamento de informações com fornecedores. Desta forma, a cadeia de suprimentos envolvendo a análise da díade Martins e seus principais fornecedores de produtos de mercearia básica (Bombril, Colgate-Palmolive, Diageo, Garoto, Johnson \& Johnson, Kraft, L’Oréal Brasil, Procter \& Gamble, Unilever) fornece um caso representativo por se tratar de empresas, em sua maioria, líderes no mercado em que atua e, no caso específico das empresas fornecedoras, com marcas de produtos solidificadas no mercado.

Para as entrevistas, elaborou-se um roteiro semiestruturado composto de dezenove questões abertas com o objetivo de compreender todo o processo de gestão da demanda entre a empresa Martins e seus principais fornecedores. O Quadro 1 mostra as empresas e seus respectivos cargos entrevistados. 
As entrevistas foram gravadas e transcritas literalmente, para posterior análise, e acompanhadas de anotações efetuadas no caderno de campo provenientes de observações dos pesquisadores e de diálogos informais mantidos com os entrevistados antes e depois das entrevistas. O tempo de duração média das entrevistas foi de uma hora e meia. As áreas escolhidas para as entrevistas na empresa Martins foram Trade Marketing, Compras, Vendas e Logística por serem estas as mais envolvidas no processo de gestão da demanda. Nas entrevistas, foi solicitado aos executivos indicar fornecedores que melhor desenvolvem a gestão da demanda com o atacadista, como também seus respectivos contatos.

Após conduzir as entrevistas com cinco empresas fornecedoras, foi solicitado aos executivos da empresa Martins indicar mais três empresas que estão no estágio inicial de desenvolvimento da gestão da demanda com o atacadista ou empresas que já desenvolvem a gestão da demanda, mas que o Martins tem mais dificuldade em conduzir o processo. Dentre todas as empresas fornecedoras indicadas, foram realizadas entrevistas com representantes da área Comercial e ou Trade Marketing das empresas, pois são estes que estão diretamente envolvidos com o processo de gestão da demanda com o Martins.

\begin{tabular}{|l|l|l|}
\hline \multirow{2}{*}{ Quadro 011 - Empresas e seus respectivos representantes entrevistados } \\
\hline \multirow{5}{*}{$\begin{array}{l}\text { Martins } \\
\text { (empresa focal) }\end{array}$} & Cargo dos entrevistados & $\begin{array}{l}\text { Quantidade } \\
\text { de entrevistas }\end{array}$ \\
\cline { 2 - 3 } & Gerente de Compras (produtos de higiene, beleza e limpeza) & 1 \\
\cline { 2 - 3 } & Gerente de Compras (produtos alimentícios) & 1 \\
\cline { 2 - 3 } & Gerente de Vendas & 1 \\
\cline { 2 - 3 } & Gerente de Trade Marketing & 1 \\
\cline { 2 - 3 } & Gerente de Planejamento Logístico & 1 \\
\cline { 2 - 3 } & Gerente de Suprimentos & 1 \\
\hline Bombril & Snalista de Suprimentos Sênior & 1 \\
\hline \multirow{2}{*}{ Colgate-Palmolive } & Gerente de Vendas & 1 \\
\cline { 2 - 3 } & Diretor de Planejamento da Demanda & 1 \\
\hline Diageo & Gerente de Trade Marketing & 1 \\
\hline \multirow{2}{*}{ Garoto } & Gerente de Trade Marketing & 1 \\
\cline { 2 - 3 } & Vendedor & 1 \\
\hline Kraft & Gerente de Vendas & 1 \\
\hline \multirow{2}{*}{ L'Oréal Brasil } & Diretor de Trade Marketing \& Merchandising & 1 \\
\cline { 2 - 3 } & Gerente Key Account & 1 \\
\hline Procter \& Gamble & Gerente de Vendas & 1 \\
\hline Unilever & Gerente de Vendas \\
\hline Total de entrevistas & & 18 \\
\hline
\end{tabular}

Fonte: Elaborado pelos autores (2011)

As empresas fornecedoras que participaram desta pesquisa são consideradas pelo atacadista como Top Supplier Service (TSS). Os critérios da empresa para ser considerado um fornecedor TSS são relevância e rentabilidade do mix de produtos para o negócio do atacadista, faturamento total anual com o Martins e nível de relacionamento. Neste sentido, o nível de relacionamento está relacionado ao interesse do fornecedor em distribuir seus produtos por meio do canal atacadista, especificamente pela empresa Martins. Este interesse se reflete na capacidade do fornecedor de 
trabalho em conjunto com o atacadista, de planejamento e de investimento, como também na aproximação de equipes das duas empresas. O Martins possui alguns fornecedores com marcas líderes no mercado, mas que não têm interesse estratégico em desenvolver parcerias com o canal indireto.

Assim, para a condução do estudo de caso, foram coletadas informações por meio de relatórios e documentos fornecidos pelas empresas, pelo material público divulgado na imprensa, por observações diretas e entrevistas. Utilizou-se observação direta na visita ao centro de distribuição da empresa Martins na cidade de Uberlândia (MG) e na visita à área de Suprimentos desta mesma empresa na qual foi observado o funcionamento do sistema de informação de ressuprimento de estoques. Antes ou após as entrevistas realizadas na empresa Martins, os pesquisadores eram convidados a tomar um café na praça central dentro do prédio da empresa. Nestes momentos, tiveram oportunidade de observar o constante movimento dos fornecedores, o relacionamento e a interação deles com os funcionários do Martins.

Os dados obtidos na pesquisa foram submetidos à análise de conteúdo que, segundo Bauer (2002), consiste no estudo de transcrições textuais de dados visando comparar, observar diferenças e categorizar fatores presentes no texto por meio do processamento da informação. As transcrições das entrevistas realizadas na pesquisa de campo foram incluídas individualmente no programa NVivo9, como fontes documentais.

O programa NVivo9 é um aplicativo que possibilita a codificação de textos e gerenciamento das informações para apoio à análise dos dados. Suas funções permitem a divisão do texto em segmentos, a codificação desses segmentos e a explicitação de todas as instâncias codificadas. À medida que a leitura atenta e cuidadosa de cada entrevista era efetuada, as ideias, conceitos ou aspectos relevantes para o tema da pesquisa foram sendo destacados e referenciados como códigos, com o apoio do programa utilizado. Convém destacar que ao se identificar um código no texto em análise, o programa NVivo9 possibilita que ele seja selecionado e associado a uma determinada categoria ou subcategoria, cadastrada a critério do usuário. A separação por temas, classificados sob a forma de categorias e subcategorias, associada à combinação de perspectivas dos diversos entrevistados, contribuiu para a interpretação dos dados.

A análise das 18 entrevistas possibilitou a codificação de 746 referências passíveis de classificação em categorias e subcategorias, bem como o número de entrevistas que representaram fontes de dados para a codificação e o número de referências obtidas.

Mensagens por e-mail foram trocadas com alguns entrevistados, como também chamadas telefônicas foram realizadas para esclarecer algumas questões que não ficaram claras durante a análise dos dados. Ao finalizar todas as análises, os resultados obtidos foram discutidos e validados separadamente com quatro representantes da empresa Martins, um da Colgate-Palmolive e um da 
Johnson \& Johnson. A duração de cada discussão foi cerca de 1 hora e 15 minutos, todas foram gravadas, pontos importantes transcritos, e foram envolvidos três executivos e uma empresa fornecedora que não haviam participado inicialmente na fase de coleta de dados, indicados pelos representantes da empresa Martins.

A discussão e a validação dos resultados com os executivos das empresas possibilitaram esclarecer alguns pontos e dúvidas que ainda estavam pendentes e aprofundar em alguns itens. A participação de executivos e outra empresa fornecedora que não foram envolvidos na fase de coleta de dados foram importantes porque surgiram novas contribuições e deu mais validade e confiabilidade aos resultados obtidos. Importante ressaltar que em nenhum momento os executivos discordaram dos resultados obtidos, pelo contrário, forneceram mais detalhes, enriquecendo a pesquisa. Portanto, ao todo, foram pesquisadas nove empresas fornecedoras do Martins.

O próximo tópico apresenta os resultados da pesquisa.

\section{Resultados}

A análise dos dados permitiu identificar que o maior desafio da gestão da demanda entre as empresas pesquisadas se refere à amplificação da demanda gerada pelas compras concentradas na última semana do mês e de oportunidade. Assim, o objetivo deste tópico é detalhar este desafio e descrever as ações que as empresas pesquisadas estão tomando para reduzir ou eliminar seus efeitos.

Em muitas situações quando o estoque no Martins está elevado, ou seja, as vendas não ocorreram na velocidade planejada, gerando inventário, as negociações com os fornecedores ocorrem uma ou duas vezes por mês. Quando as concentrações de compras no final do mês se tornam frequentes, a área de Suprimentos do fornecedor se prepara para este pico de vendas com o aumento do volume de estoque e da produção pela fábrica. Esta situação é desfavorável tendo-se em vista que representa capital de giro parado, impacta o espaço disponível para armazenamento e faz com que o pessoal da fábrica trabalhe muito num determinado período e fique ocioso em outros.

Assim, se os pedidos do Martins concentram-se no final do mês, existe uma probabilidade alta do fornecedor não conseguir atendê-los integralmente e de haver atrasos de entrega tendo-se em vista a necessidade de disponibilizar um número maior de veículos e entregar nos centros de distribuição do Martins. Esta situação pode causar rupturas de produtos. Um representante da empresa Martins menciona que, dentre as nove empresas fornecedoras pesquisadas, algumas chegam a um nível de ruptura de $10 \%$ a $20 \%$.

Além das compras concentradas no final do mês, existem também as compras de oportunidade que são situações em que o fornecedor oferece uma condição comercial atrativa para a compra de um volume maior de produtos. O volume de compras pode representar de 100 a 200 
carretas de mercadorias para serem retiradas em dois ou três dias. Desta forma, o Martins fará pedidos maiores, com condições de retiradas imediatas e, não de acordo com a demanda.

Geralmente estas compras de oportunidade estão relacionadas à necessidade do fornecedor de atingir uma meta de vendas. Muitas vezes as compras concentradas na última semana do mês geram um estoque excessivo para o próximo mês, fazendo com que o Martins não cumpra o plano acordado de compras no mês seguinte. Porém, as metas de vendas dos fornecedores continuam e, para atingi-las, estes acabam oferecendo condições comerciais atraentes para o Martins. Outro motivo das compras de oportunidade é quando o fornecedor está fechando o seu ano fiscal e precisa atingir a meta de vendas. Este processo se torna um ciclo vicioso, porque o Martins, sabendo que o fornecedor precisa atingir a meta dele, muitas vezes fica segurando o pedido até o fornecedor ceder. Um representante do Martins menciona:

Existe o interesse do fornecedor quando tem uma negociação concentrada dentro do mês. E esta negociação, de repente sai dia 28 do mês. É problema lá porque o cara da produção tem que se virar para produzir e carregar veículos. E é problema para a gente, para internalizar isto dentro da nossa capacidade de recebimento e dentro dos nossos espaços de armazenagem.

Verifica-se neste relato que as empresas assumem os custos de transação, porém ainda terão que desenvolver ações em conjunto para diminuir o nível de inventário gerado com as compras de oportunidade. Estas ações necessitarão de investimentos financeiros e não financeiros das empresas para estimular as vendas nas lojas varejistas. O aumento das vendas acarretará em mais movimentações nos armazéns do Martins e maior distribuição dos produtos, podendo ocasionar atrasos nas entregas.

A área de Vendas do Martins é impactada pelas compras de oportunidade porque precisa desenvolver, em conjunto com outras áreas da empresa e com os fornecedores, um plano de ação para vender os produtos estocados em excesso, estabelecer novas metas de vendas e comunicar a força de vendas. E a área de Compras precisa rever o planejamento desenvolvido em conjunto com o fornecedor para redefinir as metas mensais.

Segundo os entrevistados do Martins, estas compras de oportunidade são inerentes ao negócio, porém geram impactos nas áreas de Logística, de Vendas e no plano de negócios desenvolvido em conjunto entre Martins e fornecedores. O sistema de informação da empresa Martins gera os pedidos de compras, a área de Compras analisa os pedidos e, para a efetivação da ordem de fornecimento, o sistema tem que gerar uma agenda de recebimento no armazém, com data e horário para que o fornecedor possa entregar. Neste sentido, no momento do pedido, a área de Compras do Martins terá problema de agendamento de pedidos que excedam a necessidade da empresa durante um período. Então, se o Martins não tiver espaço para armazenamento dos produtos e/ou as empresas não tiverem frota de veículos disponível para a entrega das mercadorias, 
as duas empresas buscarão alternativas como locação de armazém, contratação de distribuidores, contratação de um turno extra para recebimento das mercadorias, assumindo os riscos e os custos da negociação.

Assim, como as compras de oportunidade geralmente envolvem grandes volumes e necessitam de uma programação de recebimento por parte do Martins, a área de Compras precisa envolver a área de Suprimentos na decisão. Quando a área de Suprimentos do Martins é acionada para liberar a agenda de recebimento, ela já foi comunicada da possível negociação. A área de Suprimentos entra em contato com a Logística do fornecedor para propor as retiradas e entregas. Quando não entram num acordo, os representantes comerciais das duas empresas são envolvidos (gerente de compras Martins e gerente de vendas do fornecedor). Verifica-se que, geralmente, as equipes de Logística das empresas são envolvidas e se interagem somente quando os problemas estão ocorrendo.

Constata-se que as compras de oportunidade são mais raras com os fornecedores que desenvolvem, com o atacadista distribuidor, as atividades de gestão da demanda, pois os entrevistados percebem que podem colocar todo o plano de negócios estabelecido em risco com negociações que não estão contempladas no plano. Os entrevistados reconhecem como consequências das compras de oportunidade:

- Necessidade de esforços de vendas adicionais das empresas, o que resultará em mais investimentos do fornecedor para diminuir os estoques do atacadista distribuidor;

- Preocupação em diminuir os estoques do Martins ao invés de desenvolver as categorias ou subcategorias em alguma região geográfica ou segmento de negócios;

- Dificuldades logísticas das empresas: ter que contratar veículos para entrega dos produtos, dificuldade do Martins em encaixar as entregas na sua programação de recebimento das mercadorias, ter espaço para armazenamento;

- Necessidade de revisar o plano de negócios reajustando-o.

Um entrevistado da empresa fornecedora, que está iniciando a gestão da demanda em conjunto com o Martins, reconhece que, com a implantação deste processo, pode diminuir as compras de oportunidade:

Se eu puder deixar de fazer uma venda de oportunidade para o Martins e começar a desenvolver com ele um programa todo estruturado, mensal, com prazo determinado, com desenvolvimento de uma determinada região, determinado canal, determinada marca, eu prefiro fazer isso que a compra de oportunidade. Esse tipo de desenvolvimento de trabalho com o Martins minimiza a necessidade de ter uma compra de oportunidade.

Outro entrevistado, também representante de uma empresa fornecedora que está iniciando o processo de gestão da demanda, ao ser questionado sobre o motivo pelo qual as compras 
concentradas na última semana do mês ou compras de oportunidade acontecem, respondeu: "Boa pergunta. Ninguém está olhando o detalhe e a gente não sentou junto para melhorar estas negociações. Esta é a evolução que a gente está buscando". Constata-se que o entrevistado reconhece o problema, mas não consegue identificar suas causas porque falta o alinhamento entre as equipes interfuncionais das duas empresas e o acompanhamento dos indicadores de desempenho. Este fornecedor não possui uma equipe estruturada para atender o Martins, mas já identificou a necessidade e está contratando pessoas, como também reestruturando sua equipe de Trade Marketing.

Para evitar que este processo ocorra ou para amenizar seus impactos, o Martins e os fornecedores pesquisados estão tomando algumas medidas: 1) acompanhamento constante por parte das empresas do plano de negócios e tomada de ações preventivas; 2) fornecimento de incentivos ao atacadista distribuidor e à força de vendas para que as compras do mês sejam distribuídas semanalmente; 3 ) não oferecimento de descontos e condições especiais de pagamento ao Martins; 4) discussão de alternativas de fretes para que o atacadista distribuidor recolha as mercadorias no fornecedor; 5) envolvimento constante e alinhamento das áreas de Logística das duas empresas.

A primeira medida se refere à necessidade das empresas pesquisadas de acompanhar e monitorar constantemente os indicadores de desempenho e agir de forma preventiva e não reativa. É necessário criar mecanismos de controle e feedback das situações que causam as distorções da demanda e medir a efetividade dos processos de gestão da demanda nas empresas (BAILEY; FRANCIS, 2008).

Percebe-se que os fornecedores que possuem uma estrutura mais organizada para atender o Martins, com uma equipe de Vendas e de Trade Marketing, com envolvimento da Logística, conseguem acompanhar melhor os resultados e discuti-los com o atacadista distribuidor. Assim, se as vendas às lojas varejistas não estão ocorrendo conforme planejado, antes que isto gere um aumento de inventário no Martins e, por consequência, a não emissão de pedidos para o fornecedor, a causa do problema é detectada e ações são direcionadas para resolvê-la. O acompanhamento constante do plano e o alinhamento com o Martins permitem aos gerentes de vendas dos fornecedores comunicarem e justificarem a suas áreas internas todas as ações do plano redirecionadas, para que as áreas possam alterar suas previsões.

A segunda medida está relacionada ao fornecimento de descontos financeiros para determinados volumes de mercadorias solicitados e embarcados até certa data para minimizar os impactos das compras na última semana do mês. Segundo Lee, Padmanabhan e Whang (1997) janelas maiores entre um pedido e outro de ressuprimento contribuem para o efeito da amplificação da demanda. Os entrevistados das empresas fornecedoras mencionaram que o ideal era que as compras ocorressem semanalmente e fossem em torno de $25 \%$ em relação ao valor total da compra 
mensal. Um representante do fornecedor comenta: "a empresa tem a ferramenta para tirar esta concentração do final do mês. Nós chamamos de pacing que é um percentual que a gente gera sobre as compras, mas que o cliente só ganha se ele embarcar determinado volume até determinada data". Além disso, os fornecedores também oferecem incentivos aos vendedores, fornecendo comissões diferenciadas para vendas que ocorrerem até determinadas datas do mês.

A terceira medida se refere a evitar oferecer descontos atrativos e condições especiais de pagamento que incentivem as compras em grandes quantidades pelo atacadista distribuidor. Lee, Padmanabhan e Whang (1997) confirmam que as flutuações de preços e as condições especiais de pagamento oferecidas pelo fornecedor resultam em compras que não refletem as necessidades imediatas do cliente.

A quarta medida citada pelos entrevistados se refere à tentativa de amenizar os impactos do fornecedor por meio de operações nas quais o Martins ficaria responsável pelo recolhimento da mercadoria no fornecedor. Porém, esta ação somente transfere o problema para a outra empresa, pois o Martins terá que arcar com as despesas do frete, disponibilizar veículos para a retirada dos produtos e muitas vezes o período de retirada não coincide com os veículos de rotas de retorno, tendo que enviar veículos específicos para buscar as mercadorias. Além disso, essa ação não resolveria a questão de aumento de estoque por parte do atacadista distribuidor.

Por fim, em relação à quinta medida, percebe-se que quando o Martins e o fornecedor aproximam suas equipes de Logística, as empresas ficam mais alinhadas e buscam soluções em conjunto para solucionar os problemas. Essa aproximação e discussão constante em relação às operações das empresas estão relacionadas à redução de alguns problemas logísticos como: níveis de inventário, níveis de ruptura, dificuldade de cumprimento da programação de entrega de mercadorias no armazém do Martins, compras concentradas na última semana do mês e compras de oportunidade. Um representante do fornecedor relata a sua insatisfação com a falta de discussão em conjunto de uma ação tomada pelo Martins:

Alguns indicadores não são desenvolvidos em conjunto. Por exemplo, no ano passado (2010) o Martins reduziu a cobertura de estoque para 25 dias. É um negócio complexo, eles têm 16.000 SKUs, menos gente para ficar auditando o que está acontecendo, então quanto menor for sua cobertura em dias de estoque, você tem maior risco de ter rupturas. Estes números não são tomados em conjunto. Os objetivos de inventário são arbitrários: 'tem que ser 25 dias'. Este número vem top down.

Um representante do Martins, ao ser questionado sobre estas decisões do atacadista distribuidor que não foram discutidas com o fornecedor e estão impactando a operação, menciona: "Se ele (fornecedor) trouxer as questões de alinhamento e planejamento para a minha área de Suprimentos, vai ter o bom senso de fazer em conjunto". Percebe-se então, a necessidade de interação das equipes de Logística das empresas para acordar e alinhar os indicadores de desempenho: nível de estoque e valor de estoque médio; nível de ruptura; agendamento de 
mercadorias para entrega no armazém do Martins; prazo médio que o fornecedor entrega as mercadorias no prazo acordado; volume entregue em relação ao volume solicitado e quais projetos poderiam ser desenvolvidos para redução de custos na cadeia de suprimentos.

Portanto, a aproximação das equipes de Logística das empresas pesquisadas pode reduzir os problemas logísticos identificados. Baljko (1999) e Croxton et al (2008) recomendam o trabalho conjunto inter e intraempresas para determinar as possíveis causas do efeito da variabilidade da demanda. Assim, à medida que a gestão da demanda se articula de forma interfuncional, a existência de sincronismo com outros processos e funções é fator determinante para alcançar os resultados esperados (CROXTON et al, 2008; VAN HOEK; MITCHELL, 2006).

\section{Conclusões}

Constatou-se que o compartilhamento de informações, desenvolvimento de um plano de negócios em conjunto e o seu acompanhamento diminuem o efeito da amplificação da demanda na cadeia de suprimentos analisada. Porém, verifica-se que mesmo diante de um alto nível de transparência de informações, abertura e confiança entre os agentes, como também compartilhamento de metas conjuntas, ainda existe a amplificação da demanda, ocasionando o efeito chicote.

As consequências da distorção da demanda para o atacadista distribuidor e para o fornecedor causadas pelas compras concentradas na última semana do mês e ou compras de oportunidade são confirmadas por Chen et al (2003), Fioriolli e Fogliatto (2009), Lee, Padmanabhan e Whang (1997), Stank; Daughery e Autry (1999), Taylor (2000): baixos níveis de serviços devidos a atrasos de entrega; vendas perdidas em função das rupturas de estoques; aumento de estoques; aumento do número de reprogramações de produção, por parte do fornecedor, para cobrir emergências; gestão ineficiente de recursos locais como pessoal, equipamentos e capital, pois grandes volumes requerem uma reprogramação de recebimento das mercadorias nos armazéns do Martins e redirecionamento do plano de negócios pelas equipes interfuncionais das empresas.

As consequências sistêmicas do efeito chicote, citadas por Chen et al (2003), Fioriolli e Fogliatto (2009), Lee, Padmanabhan e Whang (1997), geram para as empresas pesquisadas elevação dos custos relacionados ao excesso de estoques, queda do retorno sobre o capital investido, queda da produtividade dos funcionários que atuam nos processos produtivos e processo decisório reativo causando ruptura de planejamento.

Para evitar que este processo ocorra ou para amenizar seus impactos, algumas medidas são tomadas pelas empresas: 1) acompanhamento constante por parte das empresas do plano de negócios e tomada de ações preventivas; 2) fornecimento de incentivos ao atacadista distribuidor e à força de vendas para que as compras do mês sejam distribuídas semanalmente; 3) não oferecimento 
de descontos e condições especiais de pagamento ao Martins; 4) discussão de alternativas de fretes para que o atacadista distribuidor recolha as mercadorias no fornecedor; 5) envolvimento constante e alinhamento das áreas de Logística das duas empresas.

Alguns autores (BALJKO, 1999; CROXTON et al, 2008; LEE; PADMANABHAN; WHANG, 1997; MANGINI; MOORI; PERERA, 2007; PAIK; BAGCHI, 2007) defendem que um fluxo de informação transparente na gestão da cadeia de suprimentos pode ser a chave para reduzir as distorções da demanda. Porém, verifica-se que mesmo diante de um alto nível de transparência de informações, abertura e confiança entre os agentes, compartilhamento de visão, objetivos e suporte operacional nos indicadores de desempenho, ainda existe a amplificação da demanda, ocasionando o efeito chicote (BAILEY; FRANCIS, 2008).

Desta forma, este estudo confirmou a constatação de Bailey e Francis (2008), pois a amplificação da demanda pode ser reduzida ou eliminada com a implantação da gestão da demanda. Os resultados mostraram que não basta somente planejamento, as empresas precisam interagir constantemente para acompanhar e monitorar o plano de negócios estabelecido, buscando solucionar os problemas em conjunto.

Além disso, este estudo reforça a necessidade da implantação sistemática do processo de gestão da demanda para reduzir ou eliminar os seus desafios e, consequentemente, as empresas obterem melhores resultados financeiros. Diversos autores defendem que a implantação bem conduzida do processo de gestão da demanda permite a obtenção de vantagem competitiva (CROXTON et al 2008; HILLETOFTH; ERICSSON, 2007; HILLETOFTH; ERICSSON; CHRISTOPHER, 2009; JUTTNER; CHRISTOPHER; BAKER, 2007; MENTZER et al, 2007; MENTZER; MOON, 2005; PIRES, 2009; RAINBIRD, 2004; VOLLMANN et al, 2004; WALTERS, 2006; WALTERS; RAINBIRD, 2004), diminui os efeitos da amplificação da demanda (BAILEY; FRANCIS, 2008) e gera benefícios como a redução dos níveis de estoque, melhoria da utilização dos ativos e melhoria na disponibilidade do produto (CROXTON et al, 2008).

Apesar dos resultados apresentados neste estudo poderem ser aplicados a outras cadeias de suprimentos, o estudo é limitado a um caso específico e a abrangência de qualquer conceito ou experiência citada deve ser estudada de forma mais ampla. Trabalhos futuros poderiam ser realizados, abrangendo:

- Um estudo semelhante que utilizasse como empresa focal uma grande rede de supermercados, ou que abrangesse um número maior de cadeias de suprimentos, ou que analisasse outros elos da cadeia de suprimentos;

- Um estudo semelhante em outros setores industriais para fins de análises comparativas; 
- Um estudo quantitativo que permita validar os desafios para a implantação do processo de gestão da demanda discutidos nesta pesquisa.

\begin{abstract}
Demand management is an emerging topic in supply chain management. It is focused on a fast and adequate integration of supplier needs in order to balance and strategically align demand with operational capability in the supply chain. The demand alignment in the supply chain may pose some problems leading to inefficient customer service, poor stock rotation, and high obsolescence rate aggravated by the wide diversity of products. The objective of this study was to identify and analyze the demand management process challenges on grocery products supply chain. A case study was conducted in the wholesale company Martins and nine of its suppliers. The research revealed that the information sharing, a joint business plan development and its performance control decrease the effects of demand amplification in the supply chain analyzed. However, it turns out that even with a high level of information transparency, openness and trust between companies, as well as sharing of joint goals, there is still a demand amplification, causing the bullwhip effect.
\end{abstract}

Keywords: demand amplification; demand management; supply chain management.

\title{
Referências
}

ADEBANJO, D. Understanding demand management challenges in intermediary food trading: a case study. Supply Chain Management, v. 14, n. 3, 2009. crossref

BAILEY, K.; FRANCIS, M. Managing information flows for improved value chain performance. International Journal of Production Economics, v. 111, n. 1, 2008. crossref

BALJKO, J. L. Expert warns of ‘bullwhip effect'. Eletronic Buyers’ News, n. 1170, July, 1999.

BALLOU, R. H. The evolution and future of logistics and supply chain management. Produção, v. 16, n. 3, set/dez, 2006. crossref

BAUER, M. W. Análise de conteúdo clássica: uma revisão. In: BAUER, M. W.; GASKELL, G. (Ed.). Pesquisa qualitativa com texto, imagem e som. Manual prático. Vozes: Petrópolis. 2002.

BOWER, P. How the S\&OP process creates value in the supply chain. Journal of Business Forecasting, v. 25, 2006, p. 20-32.

CHEN, F.; DREZNER, Z.; RYAN, J. K.; SIMCHI-LEVI, D. The Bullwhip Effect: managerial insights on the impact of forecasting and information on variability in a supply chain. In: TAYUR, S.; GANESHAN, R.; MAGAZINE, M. Quantitative models for supply chain management. Norwell: Kluwer Academic Publishers, 2003.

CHRISTOPHER, M.; TOWILL, D. An integrated model for the design of agile supply chains. International. Journal of Physical Distribution and Logistics, v. 31, n. 4, 2001.

CHRISTOPHER, M.; TOWILL, D. R. Supply chain migration from lean and functional to agile and customized. Supply Chain Management: An International Journal, v. 5, n. 4, 2000.

CLAASSEN, M. F. T.; VAN WEELE, A. F.; VAN RAAIJ, E. M. Performance outcomes and success factors of vendor managed inventory (VMI). Supply Chain Management: An International Journal, v. 13, n. 6, 2008 p. $406-414$. crossref

CROXTON, K. L.; LAMBERT, D. M.; GARCÍA-DASTUGUE, S. J.; ROGERS, D. S. The Demand Management Process. In: LAMBERT, D. M. Supply Chain Management: Processes, Partnerships, Performance. Florida: Supply Chain Management Institute, 2008, p. 87-104. 
ESPER, T. L.; EllingeR, A. E.; STANK, T. P.; FLINT, D. J.; MOON, M. Demand and supply integration: a conceptual framework of value creation through knowledge management. Academy of Marketing Science, v. 38, n. 1, 2010.

FAWCETT, S. E.; MAGNAN, G. M. The rhetoric and reality of supply chain management. International Journal of Physical Distribution \& Logistics Management, v. 32, n. 5, 2002. crossref

FIORIOLLI, J. C.; FOGLIATTO, F. S. Modelagem matemática do efeito chicote em ambientes com demanda e lead time estocásticos. Pesquisa Operacional, v.29, n.1, Janeiro a Abril, 2009, p.129-151.

FRENCH JR., J.P.; RAVEN, B. The bases of social power. IN: CARTWRIGHT, D. (Ed.). Studies in social power. Ann Arbor: University of Michigan Press, 1959.

HA, B. C.; PARK, Y.K.; CHO, S. Suppliers' affective trust and trust in competency in buyers: its effect on collaboration and logistics efficiency. International Journal of Operations \& Production Management, v. 31, n. 1, 2011, p. 56-77. crossref

HILLETOFTH, P.; ERICSSON, D. Demand chain management: next generation of logistics management. Conradi Research Review, v. 4, n. 2, 2007.

HILLETOFTH, P.; ERICSSON, D.; CHRISTOPHER, M. Demand chain management: a Swedish industrial case study. Industrial Management and Data Systems, v. 109, n. 9, 2009. crossref

JUTTNER, U.; CHRISTOPHER, M.; BAKER, S. Demand chain management-integrating marketing and supply chain management. Industrial Marketing Management, v. 36, 2007.

LAMBERT, D. M. The eight essential supply chain management processes. Supply Chain Management Review, v.8, n.6, sep., 2004.

LAMBERT, D. M; COOPER, M. C. Issues in Supply Chain Management. Industrial Marketing Management, v.29, p.65-83, 2000. crossref

LAMBERT, D. M.; COOPER, M. C.; PAGH, J. D. Supply chain management: implementation issues and research opportunities. The International Journal of Logistics Management, v.9, n.2, 1998. cross ref

LAPIDE, L. Sales and operations planning Part I: the process. The Journal of Business Forecasting, v. 23, n. 3, 2004.

LEE, H.; PADMANABAHN, V.; WHANG, S. Information distortion in a supply chain: the bullwhip effect. Management Science, v. 43, n. 4, 1997. crossref

MANGINI, E. R.; MOORI, R. G.; PERERA, L. C. J. Uma Análise Investigativa do 'Efeito Chicote' na Cadeia de Suprimentos da Indústria Alimentícia. In: Encontro Nacional da Anpad, 31. 2007, Rio de Janeiro. Anais... Rio de Janeiro: ENANPAD, 2007.

MELO, D. C.; ALCÂNTARA, R. L. C. Proposição de um modelo para a gestão da demanda: um estudo entre os elos atacadista e fornecedores de produtos de mercearia básica. Gestão \& Produção, v.19, n.4, 2012. cross ref

MELO, D. C.; ALCÂNTARA, R. L. C. A gestão da demanda em cadeias de suprimentos: uma abordagem além da previsão de vendas. Gestão \& Produção, v. 18, n. 4, 2011, p. 1-16. cross ref

MENTZER, J. T.; DEWITT, W.; KEEBLER, J. S.; MIN, S.; NIX, N. W.; SMITH, C. D.; ZACHARIA, Z. G. Defining supply chain management. Journal of Business Logistics, v.22, n.2, 2001. crossref

MENTZER, J. T.; MOON, M. A. Sales forecasting management: a demand management approach. Thousand Oaks: Sage, 2005.

MENTZER, J. T.; MOON, M. A.; ESTAMPE, D.; MARGOLIS, G. Demand Management. In: MENTZER, J. T.;

MYERS, M. B.; STANK, T. P. Handbook of Global Supply Chain Management. Thousand Oaks: Sage, 2007.

MEUNIER-FITZHUGH, K. L.; PIERCY, N. F. Exploring collaboration between sales and marketing. European Journal of Marketing, v. 41, n. 7/8, 2007, p. 939 - 955. crossref 
MILLIKEN, A.L. Sales \& operations planning: building the foundation. Journal of Business Forecasting, v. 27, 2008, p. 4-12.

MIN, S.; ROATH, A. S.; DAUGHERTY, P. J.; GENCHEV, S. E.; CHEN, H.; ARNDT, A. D. ; RICHEY, R. G. Supply chain collaboration: what's happening? The International Journal of Logistics Management, v. 16, n.2, 2005. crossref

PAIK, S. K.; BAGCHI, P. K. Understanding the causes of the bullwhip effect in a supply chain. International Journal of Retail and Distribution Management, v. 35, n. 4, 2007. cross ref

PIRES, S. R. I. Gestão da cadeia de suprimentos: conceitos, estratégias, práticas e casos. São Paulo: Atlas, 2009.

RAINBIRD, M. Demand and supply chains: the value catalyst. International Journal of Physical Distribution and Logistics Management, v. 34, n. 3/4, 2004. crossref

RANKING ABAD / NIELSEN 2012. Receita do setor atacadista distribuidor cresce e chega a R\$ 164,5 bilhões. Revista Distribuição, v.232, n. 20, maio 2012.

REXHAUSEN, D.; PIBERNIK, R.; KAISER, G. Customer-facing supply chain practices-The impact of demand and distribution management on supply chain success. Journal of Operations Management, v. 30, 2012 , p. $269-281$. crossref

STANK, T. P.; KELLER, S. B.; DAUGHERTY, P. J. Supply chain collaboration and logistical service performance. Journal of Business Logistics, v. 22, n. 1, 2001. crossref

TAYLOR, D. H.; FEARNE, A. Towards a framework for improvement in the management of demand in agri-food supply chains. Supply Chain Management: An International Journal, v. 11, n. 5, 2006.

TAYLOR, D. H. Demand management in agri-food supply chains: an analysis of the characteristics and problems and a framework for improvement. The International Journal of Logistics Management, v. 17, n. 2, 2006. crossref

TROQUE, W. A. Influência das Práticas da Gestão da Cadeia de Suprimentos sobre a Gestão da Demanda: Um Modelo de Análise Conceitual. Santa Bárbara D’Oeste. 189 f. Dissertação (Mestrado). Faculdade de Engenharia, Arquitetura e Urbanismo, Programa de Pós Graduação em Engenharia de Produção, Universidade Metodista de Piracicaba, 2003.

VAN HOEK, R. I.; MITCHELL, A. J. The challenge of internal misalignment. International Journal of Logistics: Research and Applications, v. 9, n. 3, September, 2006, p. 269-281. crossref

VIEIRA, J.; YOSHIZAKI, H.; HO, L. Collaboration intensity in the Brazilian supermarket retail chain. Supply Chain Management: an international Journal, v. 14, n. 1, 2009.

VOLLMANN, T. E.; BERRY, W. L.; WHYBARK, D. C; JACOBS, F. R. Manufacturing

Planning and Control for Supply Chain Management. Boston: Mcgraw-Hill, 2004.

VOLUNTARY INTERINDUSTRY COMMERCE SOLUTIONS - VICS. Linking CPFR and S\&OP: A Roadmap to $\begin{array}{lllll}\text { Integrated } & \text { Business } & \text { Planning } & \text { Disponível }\end{array}$ http://www.vics.org/docs/committees/cpfr/CPFR_SOP_Guideline_Ver1.0Sep2010.pdf> Acesso em: 31 de outubro de 2012.

WALlACE, T. F. Sales \& Operations Planning: the how-to handbook. Cincinnati: T. F. Wallace \& Company, 2004.

WALTERS, D. Demand chain effectiveness supply chain efficiencies. Journal of Enterprise Information Management, v. 19, n. 3, 2006.

WALTERS, D., RAINBIRD, M.: The Demand Chain as an Integral Component of the Value Chain. Journal of Consumer Marketing, v. 21, n. 7, 2004. cross ref

YIN, R.K. Estudo de caso: planejamento e métodos. Porto Alegre: Bookman, 2005. 


\section{Dados dos autores}

Nome completo: Daniela de Castro Melo

Filiação institucional: Universidade Federal do Triângulo Mineiro (UFTM)

Departamento: Departamento de Engenharia de Produção

Função ou cargo ocupado: Professor Adjunto

Endereço para correspondência (bairro, cidade, estado, país e CEP): Rua Limírio Dias de Almeida, 98 Parque do Mirante, Uberaba - MG, CEP: 38081300

Telefones para contato: (34) 3331-3000

e-mail: daniela_c_melo@yahoo.com.br

Nome completo: Rosane Lucia Chicarelli Alcantara

Filiação institucional: Universidade Federal de São Carlos (UFSCar)

Departamento: Departamento de Engenharia de Produção

Função ou cargo ocupado: Professor Associado

Endereço para correspondência: Rod. Washington Luiz, Km 235 / Caixa Postal 676 / CEP:

13.565-905 /São Carlos - SP

Telefones para contato: (16) 3351-8296

e-mail: rosane@ dep.ufscar.br

Submetido em: 13/05/2013

Aceito em: 25/09/2014 